\title{
An extended modification of transmanubrial osteomuscular sparing approach: salvage resection for recurrent superior sulcus lung cancer after definitive chemoradiotherapy
}

\author{
Noriaki Sakakura, Takeo Nakada, Yusuke Takahashi, Hiroaki Kuroda \\ Department of Thoracic Surgery, Aichi Cancer Center Hospital, Nagoya, Japan \\ Correspondence to: Noriaki Sakakura, MD, PhD. Department of Thoracic Surgery, Aichi Cancer Center Hospital, 1-1 Kanokoden, Chikusa-ku, \\ Nagoya 464-8681, Japan. Email: nsakakura@aichi-cc.jp.
}

Submitted Sep 29, 2020. Accepted for publication Nov 18, 2020.

doi: 10.21037/jtd-20-3003

View this article at: http://dx.doi.org/10.21037/jtd-20-3003

This brief report accompanying a short video presents an extended modification of the transmanubrial osteomuscular sparing approach (TMA).

Among surgical procedures for anterior-ventral thorax to superior sulcus lung malignancies, classic anterior approach described by Masaoka et al. in 1979 (1), anterior transcervical-thoracic approach reported by Dartevelle et al. in 1993 (2), and TMA reported by Grunenwald and Spaggiari in 1997 (3) are famous. An alternative procedure combining the Dartevelle's method with original TMA has also been reported (4). Based on the extension of the disease, a combination of two approaches may also be considered; conventional two-step strategy, involving an original TMA followed by a lateral decubitus position, would be a common practice. When the lesion is small, it is possible to resect it using only a single approach with a slight modification. In original TMA, the transverse section of the sternum is on the level of the first intercostal space and the sternoclavicular joint is preserved. The modification presented herein consists of a lowering of the transverse section of the sternum caudally to the level of the second intercostal space (Figure 1).

We demonstrate the procedure using a salvage resection case with recurrent superior sulcus lung cancer (Video 1). The patient was a 58 -year-old man who received definitive chemoradiotherapy for a clinical T4N3M0, stage IIIC right superior sulcus lung adenocarcinoma infiltrating the brachial plexus. The lesion was definitively treated with cisplatin and vinorelbine chemotherapy, as well as radiotherapy at $60 \mathrm{~Gy}$. After 3 years, a recurrent tumor was detected on the dorsal side of the right subclavian artery on the right side of the first and second thoracic vertebrae. The lesion was diagnosed as recurrent lung cancer by needle biopsy. There were no driver gene mutations or PDL1 expression detected. Since there were no distant metastases or mediastinal lymph node metastases detected and no other nonsurgical treatment was considered effective, salvage resection was planned.

The procedure performed is summarized as follows. With the patient in the supine position, a reverse C-shaped incision was made on the cranial side of the right anterior chest. The right superior end of the sternum was cut in a reverse $L$ shape, with the transverse section caudally lowered to the level of the second intercostal space. The first and second right costal cartilages were cut. The manubrium was raised, and the sternoclavicular joint was preserved. The principle of preservation of the sternoclavicular joint is the same as in the original TMA (3). The tumor was identified on the dorsal side of the right subclavian and internal thoracic arteries. The surrounding tissue of the tumor was found to be scarred and hard due to the definitive chemoradiotherapy received previously; therefore, several samples of the surrounding tissue were dissected for intraoperative frozen section analysis, resulting in no malignant findings in the margin. The lesion was dissected from the right subclavian artery and the anterior surface of the first and second thoracic vertebrae, and the right upper lobe was partially resected. The sternum was firmly fixed using sternal pins (Super Fixsorb 30; Takiron Co., Ltd., Osaka, Japan) and sheets (Super Fixsorb MX40; Takiron Co., Ltd., Osaka, Japan), which comprised a mixture of unsintered hydroxyapatite and poly-L-lactic 

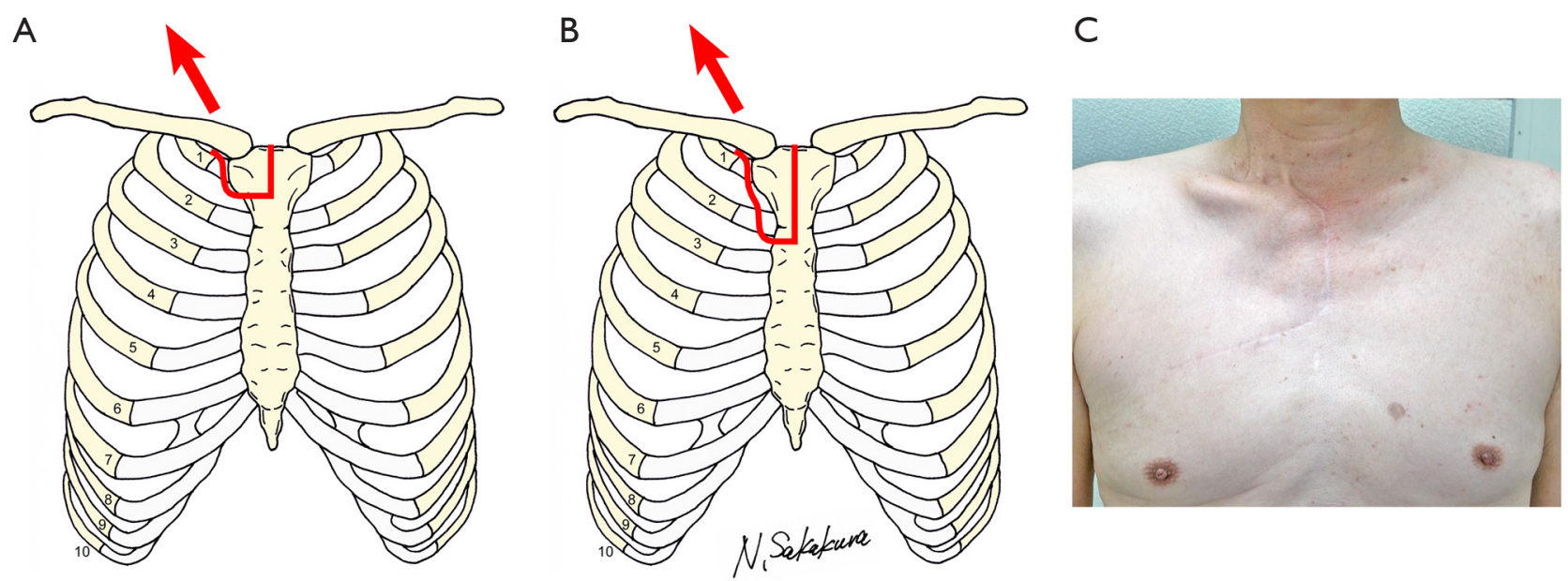

Figure 1 Schema of the incision of the bony thorax. (A) Original procedure of the transmanubrial osteomuscular sparing approach; (B) the modification presented herein. Arrows indicate the direction of the retraction of the clavicle and manubrium; $(\mathrm{C})$ the reverse $\mathrm{C}$-shaped skin incision.

acid, and No. 5 Ethibond nonabsorbable braided polyester sutures (Ethicon, Inc., Somerville, NJ, USA). The lesion was successfully resected and there was no restriction in the shoulder function. Complete resection was achieved, and no recurrence occurred postoperatively at 36 months. The initial plan for this patient was to employ a conventional two-step strategy, consisting of an original TMA followed by a lateral decubitus position. However, resection could only be achieved using this modification. As shown in the video, although the incision was small, the necessary surgical view could be obtained.

One advantage of this extended modification of TMA is the ability to view the mediastinal side as well as the superior sulcus area. This approach is a possible procedural option for lesions located in the region extending from the mediastinum to the superior sulcus. In this method, it is important to firmly fix the sternum because the portion of the sternal angle may be slightly fragile.

We described the procedure presented herein as an extended modification of TMA, but this approach may also be considered as a modification of Masaoka's trap-door procedure. During the surgery, the transverse section of the sternum was caudally lowered to the level of the second intercostal space, the first and second costal cartilages were cut, and the manubrium was raised, in order to preserve the sternoclavicular joint as similarly to original TMA. Therefore, we deem it suitable to consider this approach to be a modification of TMA.

Currently, minimally invasive procedures have been advancing significantly in the field of thoracic surgery, with thoracoscopic surgery being widely performed, and robotic surgery being introduced. Alternatively, open thoracotomy is less frequently performed, and unusual types of surgery, such as TMA, are also becoming less frequent. Nevertheless, reliable techniques for open thoracotomy remain important. Although the modification presented herein is minor, and it may be superfluous to add a comment on the classic and famous TMA, we hope that this report and the video will prompt further discussion on open thoracotomy and could be of help in daily clinical practice.

\section{Acknowledgments}

We thank Dr. Yukinori Sakao for his preoperative management of the patient and for the surgical instructions. Funding: None.

\section{Footnote}

Provenance and Peer Review: This article was a free submission to the journal. The article was sent for external peer review.

Peer Review File: Available at http://dx.doi.org/10.21037/jtd20-3003

Conflicts of Interest: All authors have completed the ICMJE uniform disclosure form (available at http://dx.doi. 
org/10.21037/jtd-20-3003). The authors have no conflicts of interest to declare.

Ethical Statement: The authors are accountable for all aspects of the work in ensuring that questions related to the accuracy or integrity of any part of the work are appropriately investigated and resolved. All procedures performed in studies involving human participants were in accordance with the ethical standards of the institutional and national research committees and with the Helsinki Declaration (as revised in 2013). Written informed consent was obtained from the patient for publication of this manuscript and any accompanying images.

Open Access Statement: This is an Open Access article distributed in accordance with the Creative Commons Attribution-NonCommercial-NoDerivs 4.0 International License (CC BY-NC-ND 4.0), which permits the noncommercial replication and distribution of the article with the strict proviso that no changes or edits are made and the original work is properly cited (including links to both the formal publication through the relevant DOI and the license). See: https://creativecommons.org/licenses/by-nc-nd/4.0/.

\section{References}

1. Masaoka A, Ito Y, Yasumitsu T. Anterior approach for tumor of the superior sulcus. J Thorac Cardiovasc Surg 1979;78:413-5.

2. Dartevelle PG, Chapelier AR, Macchiarini P, et al. Anterior transcervical-thoracic approach for radical resection of lung tumors invading the thoracic inlet. J Thorac Cardiovasc Surg 1993;105:1025-34.

3. Grunenwald D, Spaggiari L. Transmanubrial osteomuscular sparing approach for apical chest tumors. Ann Thorac Surg 1997;63:563-6.

4. Onuki T, Murasugi M, Mae M, et al. Modification of anterior approach to superior sulcus tumors. J Thorac Cardiovasc Surg 1998;116:663-4.
Cite this article as: Sakakura N, Nakada T, Takahashi Y, Kuroda H. An extended modification of transmanubrial osteomuscular sparing approach: salvage resection for recurrent superior sulcus lung cancer after definitive chemoradiotherapy. J Thorac Dis 2021;13(1):417-419. doi: 10.21037/jtd-20-3003 